\title{
International practice of corticosteroid replacement therapy in congenital adrenal hyperplasia: data from the I-CAH registry
}

\author{
Irina Bacila', Nicole Freeman', Eleni Daniel', Marija Sandrk', Jillian Bryce², Salma Rashid Ali(i)2, \\ Zehra Yavas Abali ${ }^{3}$, Navoda Atapattu', Tania A Bachega ${ }^{5}$, Antonio Balsamo ${ }^{6}$, Niels Birkebæk7, \\ Oliver Blankenstein ${ }^{8}$, Walter Bonfig ${ }^{9,10}$, Martine Cools ${ }^{11}$, Eduardo Correa Costa ${ }^{12}$, Feyza Darendeliler ${ }^{13}$, \\ Silvia Einaudi ${ }^{14}$, Heba Hassan Elsedfy ${ }^{15}$, Martijn J J Finken ${ }^{16}$, Evelien Gevers ${ }^{17,18}$, \\ Hedi L Claahsen-van der Grinten ${ }^{19}$, Tulay Guran $\mathbb{1}^{3}$, Ayla Güven ${ }^{20}$, Sabine E Hannema ${ }^{21,22}$, Claire E Higham ${ }^{23}$, \\ Violeta lotova ${ }^{24}$, Hetty J van der Kamp ${ }^{25}$, Marta Korbonits ${ }^{17}$, Ruth E Krone ${ }^{26}$, Corina Lichiardopol27, \\ Andrea Luczay ${ }^{28}$, Berenice Bilharinho Mendonca ${ }^{5}$, Tatjana Milenkovic ${ }^{29}$, Mirela C Miranda ${ }^{5}$, Klaus Mohnike ${ }^{30}$, \\ Uta Neumann ${ }^{8}$, Rita Ortolano6 ${ }^{6}$ Sukran Poyrazoglu' ${ }^{13}$, Ajay Thankamony ${ }^{31}$, Jeremy W Tomlinson ${ }^{32}$, Ana Vieites ${ }^{33}$, \\ Liat de Vries ${ }^{34,35}$, S Faisal Ahmed ${ }^{2}$, Richard J Ross' ${ }^{1}$ and Nils P Krone 1,36
}

\begin{abstract}
'Department of Oncology and Metabolism, University of Sheffield, Sheffield, UK, ²Developmental Endocrinology Research Group, University of Glasgow, Glasgow, UK, ${ }^{3}$ Pediatric Endocrinology and Diabetes, Marmara University, Istanbul, Turkey, ${ }^{4}$ Pediatric Endocrinology, Lady Ridgeway Hospital, Colombo, Sri Lanka, ${ }^{5}$ Department of Internal Medicine, University of Sao Paulo, Sao Paulo, Brazil, ${ }^{6}$ Department of Medical and Surgical Sciences, Pediatric Unit, Endo-ERN Center for Rare Endocrine Diseases, S.Orsola-Malpighi University Hospital, Bologna, Italy, ${ }^{7}$ Department of Pediatrics, Aarhus University Hospital, Aarhus, Denmark, ${ }^{8}$ Institute for Experimental Pediatric Endocrinology and Center for Chronically Sick Children, Charite - Universitätsmedizin Berlin, Berlin, Germany, ${ }^{9}$ Department of Pediatrics, Technical University Munich, Munich, Germany, ${ }^{10}$ Department of Pediatrics, Klinikum Wels-Grieskirchen, Wels, Austria,

${ }^{11}$ Pediatric Endocrinology, Internal Medicine and Pediatric Research Unit, University Hospital Ghent, Ghent University, Ghent, Belgium,

${ }^{12}$ Pediatric Surgery Service, Hospital de Clínicas de Porto Alegre, Porto Alegre, Brazil, ${ }^{13}$ Paediatric Endocrinology Unit, Istanbul University, Istanbul Faculty of Medicine, Istanbul, Turkey, ${ }^{14}$ Department of Paediatric Endocrinology, Regina Margherita Children's Hospital, University of Torino, Torino, Italy, ${ }^{15}$ Pediatrics Department, Ain Shams University, Cairo, Egypt, ${ }^{16}$ Department of Paediatric Endocrinology, Emma Children's Hospital, Amsterdam UMC, Vrije Universiteit Amsterdam, Amsterdam, Netherlands, ${ }^{17} \mathrm{Centre}$ for Endocrinology, William Harvey Research Institute, Queen Mary University London, London, UK, ${ }^{18}$ Department of Paediatric Endocrinology, Barts Health NHS Trust - Royal London Hospital, London, UK, ${ }^{19}$ Department of Pediatric Endocrinology, Radboud University Medical Centre, Nijmegen, Netherlands, ${ }^{20}$ Saglik Bilimleri University, Medical Faculty Zeynep Kamil Maternity and Children Hospital, Pediatric Endocrinology Clinic, Istanbul, Turkey, ${ }^{21}$ Department of Pediatric Endocrinology, Sophia Children's Hospital, Erasmus Medical Centre, Rotterdam, Netherlands, ${ }^{22}$ Department of Paediatrics, Leiden University Medical Centre, Leiden, Netherlands,

${ }^{23}$ Department of Endocrinology, Christie Hospital NHS Foundation Trust, Manchester, UK, ${ }^{24}$ Department of Paediatrics, Medical University of Varna, Varna, Bulgaria, ${ }^{25}$ Pediatric Endocrinology Wilhelmina Children's Hospital, University Medical Centre Utrecht, Utrecht, Netherlands, ${ }^{26}$ Department of Endocrinology and Diabetes, Birmingham Women's and Children's Hospital, Birmingham, UK, ${ }^{27}$ Department of Endocrinology, University of Medicine and Pharmacy Craiova, Craiova, Romania, ${ }^{28}$ Semmelweis University, Budapest, Hungary, ${ }^{29}$ Department of Endocrinology, Institute for Mother and Child Healthcare of Serbia 'Dr Vukan Čupić' Belgrade, Serbia, ${ }^{30}$ Department of Pediatrics, Otto-von-Guericke University, Magdeburg, Germany, ${ }^{31}$ Department of Pediatrics,
\end{abstract} University of Cambridge, Cambridge Biomedical Campus, Cambridge, UK, ${ }^{32}$ Oxford Centre for Diabetes, Endocrinology \& Metabolism, NIHR Oxford Biomedical Research Centre, Churchill Hospital, Oxford, UK, ${ }^{33}$ Centro de Investigaciones Endocrinológicas (CEDIE-CONICET), Hospital de Niños Ricardo Gutiérrez, Buenos Aires, Argentina,

${ }^{34}$ Institute for Diabetes and Endocrinology, Schneider's Children Medical Center of Israel, Petah-Tikvah, Israel, ${ }^{35}$ Sackler School of Medicine, Tel-Aviv University, Tel-Aviv, Israel, and ${ }^{36}$ Department of Medicine III, University Hospital Carl Gustav Carus, Technische Universität Dresden, Dresden, Germany

Correspondence should be addressed to N P Krone Email n.krone@sheffield.ac.uk

\begin{abstract}
Objective: Despite published guidelines no unified approach to hormone replacement in congenital adrenal hyperplasia (CAH) exists. We aimed to explore geographical and temporal variations in the treatment with glucocorticoids and mineralocorticoids in $\mathrm{CAH}$.

Design: This retrospective multi-center study, including 31 centers (16 countries), analyzed data from the InternationalCAH Registry.
\end{abstract} Printed in Great Britain

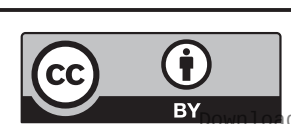

This work is licensed under a Creative Commons Attribution 4.0 International License. 
Methods: Data were collected from 461 patients aged 0-18 years with classic 21 -hydroxylase deficiency (54.9\% females) under follow-up between 1982 and 2018. Type, dose and timing of glucocorticoid and mineralocorticoid replacement were analyzed from 4174 patient visits.

Results: The most frequently used glucocorticoid was hydrocortisone (87.6\%). Overall, there were significant differences between age groups with regards to daily hydrocortisone-equivalent dose for body surface, with the lowest dose (median with interquartile range) of $12.0(10.0-14.5) \mathrm{mg} / \mathrm{m}^{2} /$ day at age 1-8 years and the highest dose of 14.0 (11.617.4) $\mathrm{mg} / \mathrm{m}^{2} /$ day at age $12-18$ years. Glucocorticoid doses decreased after 2010 in patients $0-8$ years $(P<0.001)$ and remained unchanged in patients aged 8-18 years. Fludrocortisone was used in $92 \%$ of patients, with relative doses decreasing with age. A wide variation was observed among countries with regards to all aspects of steroid hormone replacement.

Conclusions: Data from the I-CAH Registry suggests international variations in hormone replacement therapy, with a tendency to treatment with high doses in children.

European Journal of Endocrinology

(2021) 184, 553-563

\section{Introduction}

Congenital adrenal hyperplasia $(\mathrm{CAH})$ represents a group of autosomal recessive conditions leading to glucocorticoid (GC) deficiency. It is caused by defects in the steroidogenic enzymes involved in cortisol biosynthesis or the electron providing factor P450 oxidoreductase (1, 2, $3,4)$. The most common form, 21-hydroxylase deficiency (21OHD), associates significant morbidity and mortality $(5,6,7)$. Classic CAH due to $21 \mathrm{OHD}$ is characterized by a complex imbalance of adrenal steroids resulting in androgen excess, GC deficiency and, in two-thirds of affected individuals, mineralocorticoid deficiency (8). Currently, it is almost impossible to mimic the complex circadian physiology of adrenal steroid biosynthesis by oral glucocorticoid replacement regimes (9). A challenge of GC treatment in $\mathrm{CAH}$ remains meeting the adequate balance between normalization of adrenal androgens, often requiring supraphysiological doses, and avoiding GC over-exposure, to minimize negative long-term health problems $(10,11,12)$.

International guidelines aiming to optimize the medical management of CAH exist $(13,14,15)$. However, they remain relatively broad and are likely to result in variable clinical practice. Furthermore, given the variability in health care provision between different countries, it is reasonable to anticipate geographical heterogeneity in the medical management of CAH. Thus, it is likely that the approach to hormonal replacement therapy in $\mathrm{CAH}$ is not uniform across the globe, which may represent an additional challenge to optimizing management and improving health care delivery. In this study, we used information available through the InternationalCAH Registry (16) and provided evidence for significant variation in the current practice of glucocorticoids and mineralocorticoid replacement in patients with $\mathrm{CAH}$.

\section{Patients and methods}

\section{Study design, setting and participants}

We conducted a retrospective international cohort study using data recorded in the I-CAH Registry (www.i-cah. org). The I-CAH Registry is an international database of pseudonymized information on patients with CAH and is approved by the National Research Ethics Service in the United Kingdom as a research database of information collected as part of routine clinical care (16). Following informed consent from patients or guardians, data are deposited within the registry by the endocrinologist supervising their management. All patients diagnosed with $210 H D$ for whom clinical information was recorded in the I-CAH Registry until December 2018 were included in the study. Data collection was conducted using the I-DSD/ CAH data fields included in the basic module (register ID, center, country, year of birth, age on presentation, disorder type, actual diagnosis, sex assigned at birth, current gender) and longitudinal module (date of visit, age, weight, height, body surface area (BSA), cushingoid features, virilization, daily adherence to treatment, glucocorticoid type, glucocorticoid dose, timing of glucocorticoid dose, fludrocortisone dose, fludrocortisone frequency). For children data were collected from each visit for the first 
2 years of life and then, the first medical visit every year until 18 years of age; for adults, data collection included the first medical visit in every year over the last 5 years.

\section{Data analysis}

Hormone replacement analysis consisted of exploring the type of drug used (for glucocorticoids), total daily dose and dose for BSA, the timing of administrations and distribution of doses throughout the day. BSA was calculated using the Mosteller formula (17). We established the following age subgroups: less than 1 year, $1-8$ years, $8-12$ years, $12-18$ years, $18-30$ years and more than 30-year, corresponding to infancy, early childhood, middle childhood, adolescence, young adult stage and adulthood respectively. Temporary variations and changes in treatment trends were explored by separating data before and after 2010, chosen in relation to the guidance published by The Endocrine Society (14).

We expressed GC doses for BSA in hydrocortisone equivalent, using the conversion rate: $20 \mathrm{mg}$ hydrocortisone $=4 \mathrm{mg}$ prednisolone $/$ prednisone $=250 \mathrm{\mu g}$ dexamethasone $=25 \mathrm{mg}$ cortisone acetate, in relation to the suppressive effect on the growth of different types of synthetic steroids $(18,19)$. As recommended by The Endocrine Society guidelines (15), the target range for GC replacement in 21OHD was defined as 10-15 mg hydrocortisone $/ \mathrm{m}^{2} /$ day. Visits reporting intravenous doses of GC during acute deteriorations (five patient visits) were excluded from the analysis.

\section{Statistical analysis}

Data were analyzed using descriptive statistics and ANOVA, with appropriate adjustments of statistical tests used in accordance to data normality, tested graphically and by using the Shapiro-Wilk test. Hormone replacement doses between groups were compared by Kruskal-Wallis H, Mann-Whitney $\mathrm{U}$ and independent $T$ tests. A $P$ value of $<0.05$ was considered statistically significant throughout the analysis. Statistical analysis and computation were conducted using SPSS Statistics Software version 26 and GraphPad Prism version 8. In exploring aspects of gluco- and mineralocorticoid replacement (daily doses, number and timing of doses), we interpreted data from every patient visit as an independent variable. For the descriptive analysis of different treatment practices in different countries, we only included countries that had recorded at least 50 patient visits.

\section{Results}

The initial dataset included 4732 patient visits that took place between 1982 and 2018, of which only 2.6\% (6\% patients) being classified as non-classic CAH (NCCAH). Moreover, $89.3 \%$ visit related to patients younger than 18 years, with adult visits only available from three countries (seven centers). Consequently, we limited our analysis to pediatric visits involving patients with classic 21 hydroxylase deficiency (Supplementary Fig. 1, see section on supplementary materials given at the end of this article). We analyzed 4174 visits recording information on 461 patients (54.9\% females) from 16 countries and 31 centers (Supplementary Table 1).

\section{Glucocorticoid treatment}

\section{Type of glucocorticoids used}

Hydrocortisone was used for GC replacement in 90-100\% visits by all countries with one exception: in Brazil cortisone acetate was used in $51.8 \%$ visits, hydrocortisone in $27.2 \%$, dexamethasone in $13.2 \%$ and prednisolone/ prednisone in $6.7 \%$. Prednisone was used in a small number of cases: eight visits corresponding to six patients from Brazil and the United Kingdom. Dexamethasone and prednisolone were used in only $2 \%$ of visits in children younger than 12 years, and more frequently in children aged $12-18$ years (dexamethasone $27.6 \%$ and prednisolone $7.8 \%$ ). Hydrocortisone was most frequently administered following a three daily doses regimen (85\%) (Fig. 1A). In $8 \%$ of patients, different types of GC were used over time (Supplementary Table 2).

\section{Glucocorticoid administration regimes}

The timing of the GC replacement doses varied widely (Fig. 1B and C). The majority of children following a three daily GC regime administered the first dose between 6:00 and 8:00 $\mathrm{h}$, the second dose between 14:00 and 16:00 $\mathrm{h}$ and the third dose between 22:00 and 23:00 h. For children taking four daily doses, the observed trend was for the first dose to be given at 4:00 $\mathrm{h}$, the second dose between 11:00 and 12:00 $\mathrm{h}$, the third dose between 16:00 and 17:00 $\mathrm{h}$ and last dose at 21:00 $\mathrm{h}$. Of the patient visits reporting three and four daily GC administrations, a circadian dosing regime was identified in $33.1 \%$ and a reverse circadian regime in $12.1 \%$ of cases, the remaining patients receiving at least two equal doses throughout the day. There was a significant difference in the administration 

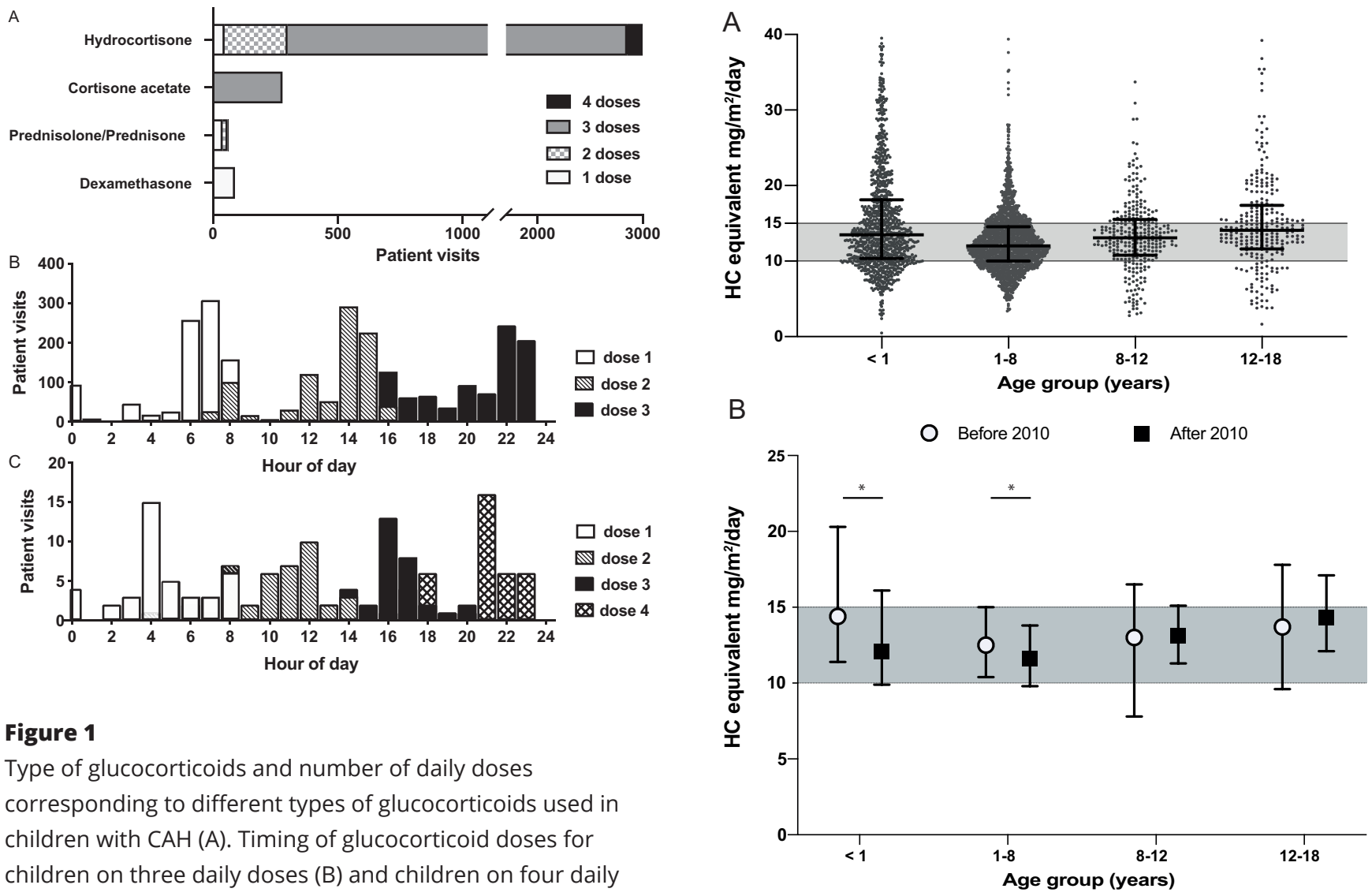

\section{Figure 1}

Type of glucocorticoids and number of daily doses corresponding to different types of glucocorticoids used in children with $\mathrm{CAH}(\mathrm{A})$. Timing of glucocorticoid doses for children on three daily doses (B) and children on four daily doses regimes (C). Each bar represents the number of patient visits recording a dose given at that time; the different patterns correspond to the order of the doses throughout the day.

strategy between age groups $(P<0.001)$, our results showing that a circadian regime was more frequently used by children aged $8-12$ and $12-18$ years (47.4 and $50.5 \%$ of patient visits, respectively), in comparison to younger children. We also found an important increase in the use of circadian regimes after 2010 for children older than 1 year of age (Supplementary Table 3).

\section{Glucocorticoid daily doses for different age groups before} and after 2010

Daily relative GC doses for BSA (Fig. 2A and Table 1) varied significantly among age groups as shown by the KruskalWallis $\mathrm{H}$ test $(P<0.001)$. Specifically, patients younger than 1 year had higher doses than children aged $1-8$ years $(P<0.001)$ and $8-12$ years $(P=0.030)$, patients aged $1-8$ years had smaller doses for BSA compared to all other age groups $(P<0.001)$, while patients aged $12-18$ years had the highest doses among all age groups with significant difference compared to the $1-8$ years $(P<0.001)$ and $8-12$

\section{Figure 2}

(A) Glucocorticoid doses expressed as relative hydrocortisone equivalent ( $\mathrm{mg} / \mathrm{m}^{2} /$ day) in different age groups. The shaded area indicates the recommended dose range of $10-15 \mathrm{mg} / \mathrm{m}^{2}$ / day. The black horizontal lines indicate the median with the interquartile range (error bars) for age group. (B) Glucocorticoid doses expressed as hydrocortisone equivalent $\left(\mathrm{mg} / \mathrm{m}^{2} /\right.$ day) in different age groups before (clear circles) and after (black squares) 2010. For each subgroup, the circles or squares correspond to the median and the error bars to the interquartile range. (*Statistical significance in comparing doses before and after 2010.) HC, hydrocortisone.

years $(P=0.004)$ group. Analyzing the clinical practice in relation to the international guidelines $(14,15)$, we found that overall the recommended upper limit of $15 \mathrm{mg} / \mathrm{m}^{2} /$ day was exceeded in $37 \%$ of patients younger than 1 year of age, $21 \%$ of $1-8$ year olds, $28 \%$ within the $8-12$ years group and $39 \%$ of patients in the $12-18$ years group. No significant difference in relative GC doses between genders were found, with the exception of patients aged 12-18 years, where females received higher doses than males $(P=0.002)$. The fluctuation of GC doses before and after 2010 was inconsistent among age and gender groups 
Table 1 Glucocorticoid doses for different age groups, before and after 2010. The doses are expressed as hydrocortisone-equivalent (median (interquartile range)).

\begin{tabular}{|c|c|c|c|c|}
\hline & $\begin{array}{l}\text { Patient } \\
\text { visits, } n \\
\end{array}$ & $\begin{array}{c}\text { Patients, } \\
n \\
\end{array}$ & Dose, $\mathrm{mg} / \mathrm{m}^{2} /$ day & $\begin{array}{c}\text { P-value } \\
\text { (before vs } \\
\text { after) }\end{array}$ \\
\hline $0-1$ years & & & & $<0.001$ \\
\hline Overall & 1037 & 375 & $13.4(10.3-18.1)$ & \\
\hline Before & 527 & 197 & 14.3 (11.4-20.3) & \\
\hline After & 546 & 178 & $12.2(9.9-16.1)$ & \\
\hline $1-8$ years & & & & $<0.001$ \\
\hline Overall & 1893 & 420 & $12.0(10.0-14.5)$ & \\
\hline Before & 823 & 187 & $12.5(10.3-15.0)$ & \\
\hline After & 1061 & 233 & $11.6(9.8-13.9)$ & \\
\hline $8-12$ years & & & & 0.553 \\
\hline Overall & 288 & 89 & $13.0(10.7-15.5)$ & \\
\hline Before & 104 & 24 & $13.0(7.8-16.5)$ & \\
\hline After & 184 & 65 & $13.0(11.3-15.1)$ & \\
\hline $12-18$ years & & & & 0.235 \\
\hline Overall & 259 & 78 & $14.0(11.6-17.4)$ & \\
\hline Before & 114 & 22 & $13.7(9.6-17.8)$ & \\
\hline After & 145 & 56 & $14.3(12.1-17.1)$ & \\
\hline
\end{tabular}

and subgroups (Fig. 2B, Table 1 and Supplementary Tables $4,5)$.

Taking the variable growth-suppressive effect of different artificial GCs into consideration, we explored the variations in the HC-equivalent dose for BSA across age groups for the different types of drugs used (Table 2). Thus, the HC-equivalent doses for BSA were comparable to those of hydrocortisone in children treated with cortisone acetate for all age groups. The use of dexamethasone and prednisolone was limited to a very small number of cases, but there was a tendency to exceed the recommended dose range.

\section{Glucocorticoid replacement practice in different countries}

This analysis only included the 11 countries that recorded 50 or more patient visits. A comparison of hormone replacement between different countries revealed large variations in types of medication, doses and regimens used. While over $90 \%$ of countries/centers used hydrocortisone as the preferred GC to treat children, in Brazil the use of cortisone acetate was reported in $51.8 \%$ of patient visits, due to limited availability of hydrocortisone. Of the 33 patients treated with cortisone acetate, four patients received exclusively cortisone acetate (during visits recorded before and after 2010), 12 patients were initially treated with cortisone acetate, which was then changed to hydrocortisone at different
Table 2 Relative doses for different types of glucocorticoids used in children. The doses are expressed as HC-equivalent (median (interquartile range)).

\begin{tabular}{|c|c|c|c|}
\hline & $\begin{array}{l}\text { Patient } \\
\text { visits, } n\end{array}$ & Patients, $n$ & Dose, $\mathrm{mg} / \mathrm{m}^{2} /$ day \\
\hline \multicolumn{4}{|c|}{$0-1$ years } \\
\hline $\mathrm{HC}$ & 997 & 338 & 13.5 (10.4-18.3) \\
\hline CA & 55 & 22 & $11.4(9.6-15.4)$ \\
\hline DEX & 3 & 3 & $17.6-20.5$ \\
\hline PRED & 18 & 4 & $8.7(6.4-16.0)$ \\
\hline \multicolumn{4}{|c|}{$1-8$ years } \\
\hline $\mathrm{HC}$ & 1740 & 344 & $12.0(10.0-14.4)$ \\
\hline CA & 139 & 23 & $12.6(10.1-16.5)$ \\
\hline DEX & 1 & 1 & 16.7 \\
\hline PRED & 13 & 5 & $6.1(5.4-22.5)$ \\
\hline \multicolumn{4}{|c|}{$8-12$ years } \\
\hline $\mathrm{HC}$ & 209 & 68 & $12.9(11.3-15.2)$ \\
\hline CA & 73 & 17 & $13.0(7.6-16.0)$ \\
\hline DEX & 3 & 3 & $20.5-24.2$ \\
\hline PRED & 3 & 2 & $20.8-19.8$ \\
\hline \multicolumn{4}{|c|}{$12-18$ years } \\
\hline $\mathrm{HC}$ & 114 & 46 & $13.6(11.0-15.8)$ \\
\hline CA & 44 & 12 & $14.0(8.8-14.8)$ \\
\hline DEX & 81 & 20 & $13.8(12.0-20.8)$ \\
\hline PRED & 20 & 11 & $21.3(13.9-25.4)$ \\
\hline
\end{tabular}

CA, cortisone acetate; DEX, dexamethasone; HC, hydrocortisone; PRED, prednisolone.

ages between 1 month and 10 years (for all patients hydrocortisone was started after 2014), 14 patients were treated with cortisone acetate until 12-16 years of age, then the treatment was changed to dexamethasone; two patients initially received cortisone acetate, followed by prednisolone between $4-14$ and 10-15 years, respectively, then dexamethasone. The use of circadian administration regimes varied among countries between 0 and 51.3\% of patient visits and that of reverse circadian, between 5.0 and $27.9 \%$ (Supplementary Table 6). Exploring replacement doses, there were wide variations between countries, especially for children younger than 8 years of age (Fig. 3, Table 3 and Supplementary Table 7). Observing visits recorded in neonates, we noted different strategies of initiating GC replacement, with six of ten countries using hydrocortisone doses above $7.5 \mathrm{mg} /$ day and some having a large variation in doses as wide as $2-15 \mathrm{mg} /$ day (corresponding to $6.6-71.8 \mathrm{mg} / \mathrm{m}^{2} /$ day HC-equivalent) (Supplementary Table 8). While for the majority of neonates GC replacement consisted of hydrocortisone, six neonates were started on cortisone acetate (dose range $3-17.5 \mathrm{mg} /$ day, HC-equivalent range $10.5-58.3 \mathrm{mg} / \mathrm{m}^{2} /$ day), five neonates started on prednisolone (dose range 0.4-1 mg/day, $5-21.1 \mathrm{mg} / \mathrm{m}^{2} /$ day HC-equivalent) and one 


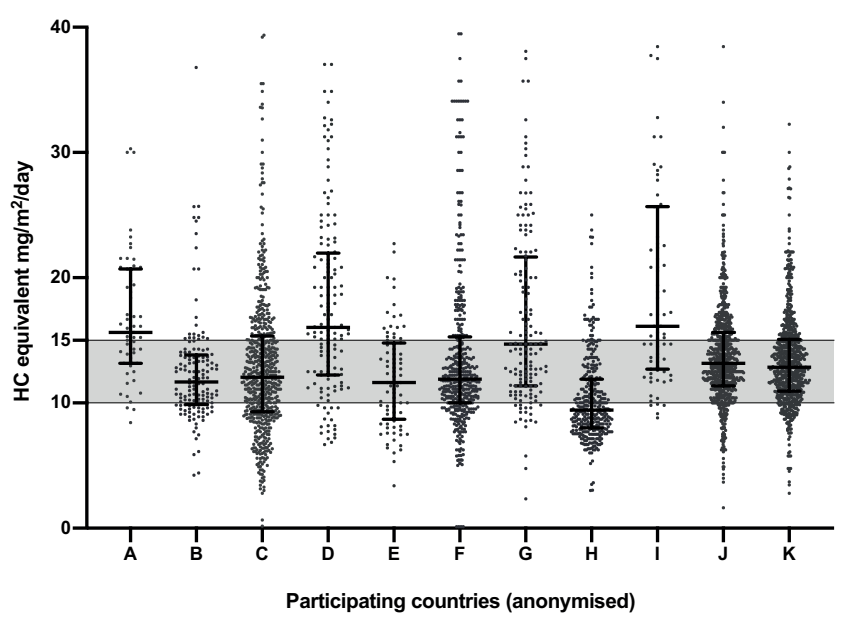

Figure 3

Glucocorticoid doses used in children from different countries, expressed as hydrocortisone equivalent ( $\mathrm{mg} / \mathrm{m}^{2} /$ day). The shaded area indicates the recommended dose range of 10-15 $\mathrm{mg} / \mathrm{m}^{2} /$ day. The black horizontal lines indicate the median with the interquartile range (error bars) for each country. The countries included in the analysis were anonymized. We only included in the analysis countries that had recorded at least 50 patient visits. $\mathrm{HC}$, hydrocortisone.

started on dexamethasone $0.075 \mathrm{mg} /$ day $\left(17.8 \mathrm{mg} / \mathrm{m}^{2} /\right.$ day HC-equivalent). One center actively reduced the GC doses over the first 1-3 months of life, while in the other countries initial neonatal doses were maintained, with a slowly decreasing relative dose over time.

Table 3 Glucocorticoid doses (HC-equivalent) used in children from different countries. The results are expressed in percentages in relation to a number of patient visits. Only the countries with a number of patient visits $\geq 50$ were included in the analysis.

\begin{tabular}{|c|c|c|c|c|c|}
\hline \multirow[b]{2}{*}{ Country* } & \multirow{2}{*}{$\begin{array}{l}\text { Patient } \\
\text { visits, } n\end{array}$} & \multirow[b]{2}{*}{ Patients, $n$} & \multicolumn{3}{|c|}{$\begin{array}{c}\text { Daily GC doses, } \\
\mathrm{mg} / \mathrm{m}^{2} / \text { day }\end{array}$} \\
\hline & & & $<10(\%)$ & $10-15(\%)$ & $>15(\%)$ \\
\hline A & 56 & 13 & 5.4 & 35.7 & 58.9 \\
\hline$B$ & 141 & 24 & 27.0 & 56.0 & 17.0 \\
\hline$C$ & 599 & 57 & 32.2 & 41.0 & 26.7 \\
\hline$D$ & 145 & 17 & 12.3 & 28.1 & 58.9 \\
\hline$E$ & 88 & 22 & 37.5 & 38.6 & 23.9 \\
\hline $\mathrm{F}$ & 441 & 57 & 24.0 & 50.1 & 25.9 \\
\hline G & 153 & 27 & 12.4 & 41.8 & 45.8 \\
\hline $\mathrm{H}$ & 350 & 56 & 57.3 & 32.5 & 10.0 \\
\hline I & 50 & 9 & & 24.5 & 75.5 \\
\hline J & 760 & 81 & 11.3 & 59.0 & 29.6 \\
\hline $\mathrm{K}$ & 693 & 78 & 13.5 & 59.5 & 25.2 \\
\hline
\end{tabular}

*Country name is anonymized.

\section{Fludrocortisone replacement}

Ninety-two percent of patients were treated with fludrocortisone. The majority of patient visits $(60.2 \%)$ reported a single daily dose of fludrocortisone, $29.8 \%$ two and $4.7 \%$ three daily doses; for the remaining visits, fludrocortisone frequency was not specified.

The total daily dose of fludrocortisone ranged between 50 and $200 \mu \mathrm{g} /$ day for the vast majority of patients of all ages, however, relative fludrocortisone doses varied widely across age subgroups (Fig. 4). We identified an increase in the dose after 2010 for all ages for both total and relative daily doses (Table 4), while no significant differences were detected between gender groups (Supplementary Table 9). Comparing doses of fludrocortisone between countries revealed variations across age groups (Supplementary Table 10).
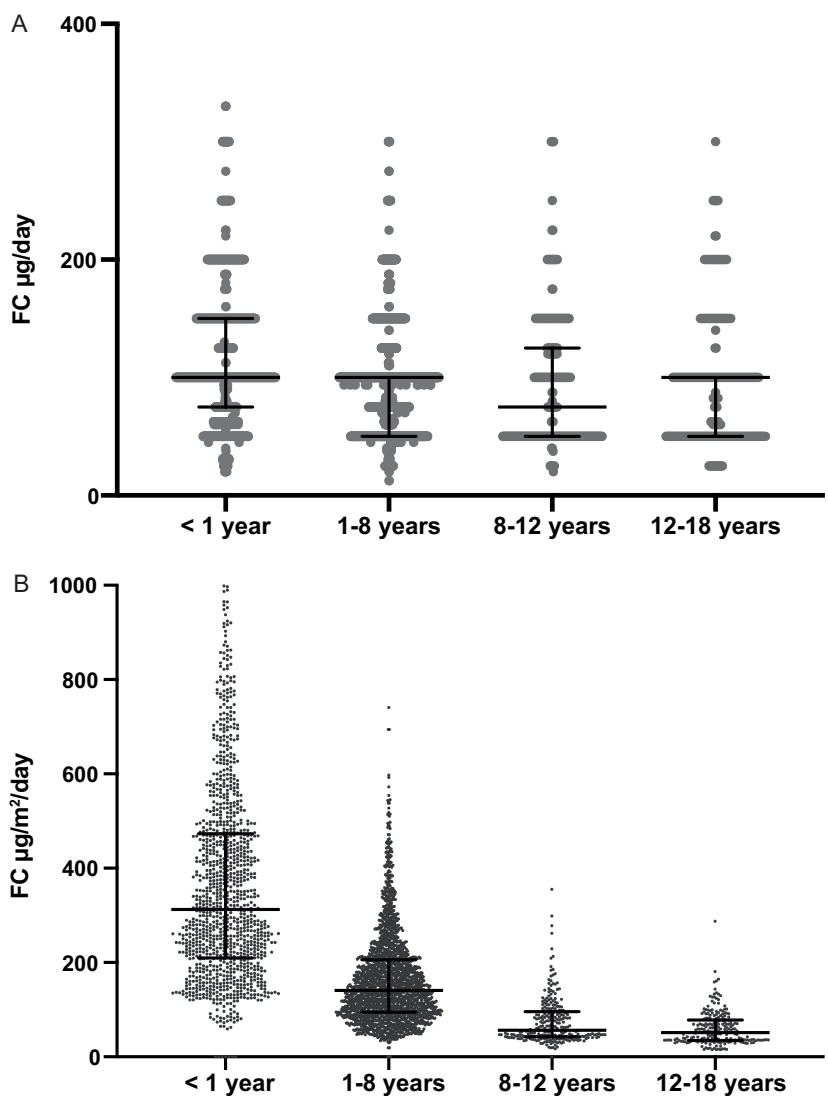

Figure 4

Absolute $(A)$ and relative $(B)$ fludrocortisone (FC) doses for different age groups, expressed in $\mu g /$ day and $\mu \mathrm{g} / \mathrm{m}^{2} /$ day, respectively. The black horizontal lines indicate the median with the interquartile range (error bars) for age group. 
Table 4 Fludrocortisone doses for different age groups, before and after 2010.

\begin{tabular}{|c|c|c|c|c|}
\hline & $\begin{array}{l}\text { Patient } \\
\text { visits, } n\end{array}$ & $\begin{array}{c}\text { Patients, } \\
n\end{array}$ & $\begin{array}{c}\text { Dose, median } \\
\text { (IQR) }\end{array}$ & P* \\
\hline \multicolumn{5}{|l|}{ 0-1 year } \\
\hline$A D, \mu g / d a y$ & & & & $<0.001$ \\
\hline Overall & 1218 & 379 & $100(75-150)$ & \\
\hline Before & 621 & 201 & $100(62.5-150)$ & \\
\hline After & 597 & 178 & $100(75-150)$ & \\
\hline $\mathrm{RD}, \mu \mathrm{g} / \mathrm{m}^{2} /$ day & & & & $<0.001$ \\
\hline Overall & 1143 & 372 & 312 (209-473) & \\
\hline Before & 567 & 195 & $279(188-416)$ & \\
\hline After & 576 & 177 & $365(228-536)$ & \\
\hline \multicolumn{5}{|l|}{$1-8$ years } \\
\hline AD, $\mu \mathrm{g} /$ day & & & & 0.016 \\
\hline Overall & 2142 & 417 & $100(50-100)$ & \\
\hline Before & 921 & 185 & $94(50-100)$ & \\
\hline After & 1221 & 233 & $100(50-100)$ & \\
\hline $\mathrm{RD}, \mu \mathrm{g} / \mathrm{m}^{2} /$ day & & & & 0.001 \\
\hline Overall & 2093 & 414 & 139 (94-205) & \\
\hline Before & 877 & 181 & $149(99-212)$ & \\
\hline After & 1216 & 233 & $134(90-195)$ & \\
\hline \multicolumn{5}{|l|}{$8-12$ years } \\
\hline AD, $\mu g /$ day & & & & $<0.001$ \\
\hline Overall & 278 & 85 & $75(50-125)$ & \\
\hline Before & 81 & 21 & $50(50-75)$ & \\
\hline After & 197 & 64 & $100(50-150)$ & \\
\hline $\mathrm{RD}, \mu \mathrm{g} / \mathrm{m}^{2} /$ day & & & & $<0.001$ \\
\hline Overall & 262 & 82 & 56 (42-95) & \\
\hline Before & 76 & 19 & $45(38-55)$ & \\
\hline After & 186 & 63 & 74 (44-107) & \\
\hline \multicolumn{5}{|l|}{$12-18$ years } \\
\hline $\mathrm{AD}, \mu \mathrm{g} / \mathrm{day}$ & & & & $<0.001$ \\
\hline Overall & 238 & 72 & $100(50-100)$ & \\
\hline Before & 75 & 19 & $50(50-50)$ & \\
\hline After & 163 & 53 & $100(60-150)$ & \\
\hline $\mathrm{RD}, \mu \mathrm{g} / \mathrm{m}^{2} / \mathrm{day}$ & & & & $<0.001$ \\
\hline Overall & 221 & 71 & $51(34-77)$ & \\
\hline Before & 74 & 18 & $35(29-44)$ & \\
\hline After & 147 & 53 & $63(41-91)$ & \\
\hline
\end{tabular}

*Presents the statistical difference (Mann-Whitney $\mathrm{U}$ ) in doses between the two time (before and after 2010) intervals. $A D$, absolute dose; $R D$, relative dose.

\section{Discussion}

Our study explored global trends of hormone replacement therapy in children with $21 \mathrm{OHD}$, providing the first general overview of the medical management of $\mathrm{CAH}$ for a wide range of countries across the world. Previous data on this topic consisted mainly of literature reviews and national cohort studies (20), which made comparisons difficult.

Overall, the types of GC used across different age groups was in line with the recommendation of international guidelines. Hydrocortisone was commonly used in children most likely based on its reduced halflife and risk of adverse effects, especially in relation to growth suppression $(19,21,22)$. Of note, cortisone acetate was used in a relatively high number of children and young people in Brazil due to lack of availability of oral hydrocortisone preparations. Nevertheless, in over $90 \%$ of patients cortisone acetate was replaced by another $\mathrm{GC}$ at a later stage. We noted that in some cases this was done in younger, prepubertal children after 2014, most likely following better access to hydrocortisone preparations. In contrast, for patients who were born and diagnosed before 2000, dexamethasone replaced cortisone acetate after the age of 12 years. While we do not have information regarding the clinical reasoning that led to these changes, we can speculate that the timing is related to the completion of linear growth. Using cortisone acetate in children with 21OHD is in line with international recommendations; however, previous publications described its variable bioactivity in relation to the dependency on 11ß-hydroxysteroid dehydrogenase type 1, suggesting higher variability of therapeutic efficiency $(23,24)$. We observed a number of children visits reporting the use of dexamethasone and prednisolone. The published guidelines advise against using long-acting GC in children due to the significant growth-suppressive effect, especially in the case of dexamethasone $(14,15)$. Since the use of dexamethasone was mainly limited to children aged 12-18 years, one might argue that patients in this age group may have completed linear growth and had more significant problems with complying to a three-daily glucocorticoid regime. However, it is important to highlight the impact of the type of GC used on other health outcomes, as hydrocortisone has been also shown to be associated with lower prevalence of metabolic comorbidities and better bone health in $\mathrm{CAH}$ in comparison to dexamethasone $(20,25,26)$.

The wide variations in the timing of the GC doses may relate to the ongoing debate regarding the optimal GC regimen. The majority of children received three or four daily doses of short acting GC, which resonates with previous research focused on optimizing hydrocortisone replacement. Earlier studies demonstrated the high bioavailability and fast clearance of hydrocortisone, recommending frequent and modest daily administrations to better mimic the physiological cortisol profiles (27). Furthermore, clinical studies in patients with adrenal insufficiency recommended the use of three rather than two daily hydrocortisone doses, based on improved cortisol profiles $(28,29,30)$. We identified a rise in the use of circadian administration regimes after 2010, which is likely related to the increasing focus on glucocorticoid regimes following a more physiological 
circadian pattern (31). Despite limited research evidence assessing the benefits of circadian hormone replacement in $\mathrm{CAH}$, it represents the most commonly employed therapy in clinical practice, based on theoretical and practical reasons, aiming to mimic the physiology of the hypothalamic-pituitary-adrenal axis (32). Moreover, it is well established that evening hydrocortisone doses are associated with increased disturbances of glucose regulation, including insulin resistance, in comparison to morning administrations (33).

Daily glucocorticoid doses exceeded the recommended range of $10-15 \mathrm{mg} / \mathrm{m}^{2} /$ day in a third of children younger than 1 year and between 12 and 18 years. However, there was a marked reduction in the percentage after 2010 for children younger than 8 years. This may relate to the publication of the international guidelines in 2002 and $2010(13,14)$. The reason for the absence of a similar effect in children aged 8-18 years remains unclear. However, adolescents are known to have reduced compliance, together with an increasing degree of independence and reduced parental supervision (34). In addition, cortisol pharmacokinetics are altered at puberty in children with $\mathrm{CAH}$ by the decreased cortisol re-activation, secondary to reduced $11 ß$-hydroxysteroid dehydrogenase type 1 activity caused by the physiological rise of growth hormone and IGF1 $(35,36)$.

A broad variation between different countries in the approach to GC replacement therapy was observed. This finding is not entirely unexpected considering previously reported variations in GC regimens for different centers within the United Kingdom (37). In some countries the recommended glucocorticoid dose range for children was exceeded in as many as $75 \%$ of patient visits, while other countries recorded doses below $10 \mathrm{mg} / \mathrm{m}^{2}$ per day in up to $57 \%$ of cases. Overall, infants received very high relative doses of GC reaching above $30 \mathrm{mg}$ HC-equivalent $/ \mathrm{m}^{2}$ per day. In neonates there were particularly marked differences in clinical practice, with half of the countries using hugely variable dose ranges between $4.2-75 \mathrm{mg} /$ $\mathrm{m}^{2}$ per day HC-equivalent. Only one center actively reduced GC doses over the weeks following initiation of treatment in a consistent manner. Importantly, studies analyzing growth in children with simple virilizing $\mathrm{CAH}$ and delayed treatment found accelerated growth only after the first $12-18$ months of life $(38,39)$, which appears to be a consequence of androgen insensitivity in infancy (40). In addition, the dose-dependent negative effect of GC on linear growth is known and the suppressive action is more marked during age intervals of high growth velocity, including infancy $(41,42)$. Moreover, there is increased risk of developing metabolic and cardiovascular comorbidities in CAH (43), associated with chronic GC overexposure (44). Although such comorbidities are only becoming fully apparent in adulthood, there is increasing evidence of the onset during childhood (45). These points emphasize the importance of treatment with the lowest possible dose of glucocorticoids by actively reducing cumulative GC doses from a young age starting in infants and young children.

The large majority of fludrocortisone doses in children were within the recommended range of 50-200 $\mu \mathrm{g} /$ day (15). However, high relative doses were used in younger individuals, with doses up to $800 \mu \mathrm{g} / \mathrm{m}^{2}$ per day and $600 \mu \mathrm{g} / \mathrm{m}^{2}$ per day in the under 1 year old and 1-8 years old group, respectively. This trend was consistent across different countries. We could not assess the practice in relation to the dosing strategies used and in the absence of information regarding clinical and biochemical standards of control it is not possible to estimate overtreatment. While there is evidence of renal resistance to mineralocorticoids in infants $(46,47)$, it was also shown that fludrocortisone treatment is associated with hypertension in children with CAH (48) and there is a correlation between blood pressure and fludrocortisone dose in infants (49). Thus, our findings indicate that the use of absolute doses may lead to overtreatment with fludrocortisone, suggesting a potential benefit to using relative doses of fludrocortisone at least in young children to fine-tune mineralocorticoid replacement.

The aim of this study was to provide an overview on the current practice of hormone replacement therapy in patients with $\mathrm{CAH}$ and we focused mainly on the types of medication used, doses and timing of administration. Thus, we acknowledge the absence of clinical and biochemical data as a weakness of the study and identify the need in the future for more in-depth analysis, including such information, in order to increase the clinical relevance of these findings. Another limitation related to data collection, consisting of the overall modest number of countries providing information on patients with CAH by using the I-CAH Registry, as a limited amount of data was available outside of Europe and South America. Moreover, the small number of adult patient visits recorded led to their exclusion from the analysis. However, the I-CAH registry allowed for analysis of a very large dataset in a rare condition, highlighting the value of real-world data and the benefit of using an international registry as a platform for exploring global clinical practice to address questions relevant to improving patient management. 
Overall, our results suggest that hormone replacement therapy in children and young persons with classic $210 H D$ varies widely across different age groups and different countries. It appears that some of these discrepancies relate to physicians' preference rather than only to physiological difference between individuals. To understand these differences in clinical practice further evidence exploring the interdependency of different management strategies including $\mathrm{CAH}$ monitoring methods is urgently warranted. In addition, future research should explore if different clinical practices are associated with differences in long-term outcome in CAH.

\section{Supplementary materials}

This is linked to the online version of the paper at https://doi.org/10.1530/ EJE-20-1249.

\section{Declaration of interest}

R J M Ross is a Director of Diurnal Ltd. Hedi L Claahsen-van der Grinten and Jeremy $\mathrm{W}$ Tomlinson are on the editorial board of EJE. They were not involved in the review or editorial process for this paper, on which they are listed as an author.

\section{Funding}

This project has received support from the I-CAH Registry project that receives unrestricted education grants from Diurnal Ltd and Neurocrine Biosciences. The initial development of the Registry was supported by the Medical Research Council (G1100236), the Seventh European Union Framework Program (201444) and the European Society for Paediatric Endocrinology Research Unit. S R A is supported by the Gardiner Lectureship at the University of Glasgow. N P K is supported by the German Research Foundation (KR3363/3-1).

\section{Data availability}

The datasets generated or analyzed during the current study are not available publicly but available to access through a data sharing agreement available at https://idsdorg.files.wordpress.com/2020/05/i-dsd-i-cah-datasharing-agreement.docx.

\section{Author contribution statement}

Nils P Krone, Irina Bacila, Jillian Bryce, Salma Ali, and S Faisal Ahmed conceptualized and designed the study, designed the data collection instruments, coordinated and supervised data collection, performed the initial analyses, drafted the initial manuscript, and approved the final manuscript as submitted. Irina Bacila and Nicole Freeman undertook the statistical analyses. All authors contributed to data acquisition, revision of the manuscript and have read and approved the final report. All authors take public responsibility and accountability for the results.

\section{Acknowledgements}

This work would not be possible without the patients and the parents of the children with $\mathrm{CAH}$ whose data have been included in the I-CAH Registry. The author would also like to thank the support of the following reference centers that participate in the European Reference Network for Rare Endocrine Conditions (Endo-ERN): Klinikum WelsGrieskirchen, Center for Pediatric Endocrinology; Ghent University Hospital; MHAT Sveta Marina, Varna; Aarhus University Hospital; Charité Universitätsmedizin Berlin; Otto-von-Guericke University, Magdeburg; Ludwig-Maximilian-University Munich; Semmelweis University, Budapest; Azienda Ospedaliera Sant'Orsola Malpighi, Bologna; Azienda Ospedaliero Universitaria Città della Salute e della Scienza di Torino; AmsterdamUniversity Medical Center, Leiden University Medical Center; Radboud University Nijmegen Medical Center; Erasmus Medical Center Rotterdam; University Medical Center Utrecht; University Hospitals Birmingham NHS Foundation Trust; NHS Greater Glasgow and Clyde Board; Barts Health NHS Foundation Trust; Central Manchester University Hospitals NHS Foundation Trust.

\section{References}

1 Miller WL \& Auchus RJ. The molecular biology, biochemistry, and physiology of human steroidogenesis and its disorders. Endocrine Reviews 201132 81-151. (https://doi.org/10.1210/er.2010-0013)

2 Krone N, Dhir V, Ivison HE \& Arlt W. Congenital adrenal hyperplasia and P450 oxidoreductase deficiency. Clinical Endocrinology 200766 162-172. (https://doi.org/10.1111/j.1365-2265.2006.02740.x)

3 Webb EA \& Krone N. Current and novel approaches to children and young people with congenital adrenal hyperplasia and adrenal insufficiency. Best Practice and Research: Clinical Endocrinology and Metabolism 201529 449-468. (https://doi.org/10.1016/j. beem.2015.04.002)

4 Merke DP \& Auchus RJ. Congenital adrenal hyperplasia due to 21-hydroxylase deficiency. New England Journal of Medicine 2020383 1248-1261. (https://doi.org/10.1056/NEJMra1909786)

5 Falhammar H, Frisén L, Norrby C, Hirschberg AL, Almqvist C, Nordenskjöld A \& Nordenström A. Increased mortality in patients with congenital adrenal hyperplasia due to 21-hydroxylase deficiency. Journal of Clinical Endocrinology and Metabolism 201499 E2715-E2721. (https://doi.org/10.1210/jc.2014-2957)

6 Engberg H, Butwicka A, Nordenström A, Hirschberg AL, Falhammar H, Lichtenstein P, Nordenskjöld A, Frisén L \& Landén M. Congenital adrenal hyperplasia and risk for psychiatric disorders in girls and women born between 1915 and 2010: a total population study. Psychoneuroendocrinology 201560 195-205. (https://doi. org/10.1016/j.psyneuen.2015.06.017)

7 Rangaswamaiah S, Gangathimmaiah V, Nordenstrom A \& Falhammar H. Bone mineral density in adults with congenital adrenal hyperplasia: a systematic review and meta-analysis. Frontiers in Endocrinology 202011 493. (https://doi.org/10.3389/ fendo.2020.00493)

8 El-Maouche D, Arlt W \& Merke DP. Congenital adrenal hyperplasia. Lancet 2017390 2194-2210. (https://doi.org/10.1016/S01406736(17)31431-9)

9 Grossman A, Johannsson G, Quinkler M \& Zelissen P. Therapy of endocrine disease: perspectives on the management of adrenal insufficiency: clinical insights from across Europe. European Journal of Endocrinology 2013169 R165-R175. (https://doi.org/10.1530/EJE-130450)

10 Alwashih MA, Watson DG, Andrew R, Stimson RH, Alossaimi M, Blackburn G \& Walker BR. Plasma metabolomic profile varies with glucocorticoid dose in patients with congenital adrenal hyperplasia. Scientific Reports 20177 17092. (https://doi.org/10.1038/s41598-01717220-5)

11 Arlt W, Willis DS, Wild SH, Krone N, Doherty EJ, Hahner S, Han TS, Carroll PV, Conway GS, Rees DA et al. Health status of adults with congenital adrenal hyperplasia: a cohort study of 203 patients. Journal of Clinical Endocrinology and Metabolism 201095 5110-5121. (https://doi.org/10.1210/jc.2010-0917) 
12 Bancos I, Hahner S, Tomlinson J \& Arlt W. Diagnosis and management of adrenal insufficiency. Lancet: Diabetes and Endocrinology 20153 216-226. (https://doi.org/10.1016/S22138587(14)70142-1)

13 Clayton PE, Miller WL, Oberfield SE, Ritzen EM, Sippell WG, Speiser PW, Hintz RL \& Savage MO. Consensus: consensus statement on 21-hydroxylase deficiency from the Lawson Wilkins Pediatric Endocrine Society and the European Society for Paediatric Endocrinology. Journal of Clinical Endocrinology and Metabolism 2002 87 4048-4053. (https://doi.org/10.1159/000065490)

14 Speiser PW, Azziz R, Baskin LS, Ghizzoni L, Hensle TW, Merke DP, Meyer-Bahlburg HFL, Miller WL, Montori V, Oberfield SE et al. Congenital adrenal hyperplasia due to steroid 21-hydroxylase deficiency: an Endocrine Society clinical practice guideline (vol 95, pg 4133, 2010). Journal of Clinical Endocrinology and Metabolism 201095 S137-S137. (https://doi-org.sheffield.idm.oclc.org/10.1210/ jc.2018-02371)

15 Speiser PW, Arlt W, Auchus RJ, Baskin LS, Conway GS, Merke DP, Meyer-Bahlburg HFL, Miller WL, Murad MH, Oberfield SE et al. Congenital adrenal hyperplasia due to steroid 21-hydroxylase deficiency: an Endocrine Society clinical practice guideline. Journal of Clinical Endocrinology and Metabolism 2018103 4043-4088. (https:// doi.org/10.1210/jc.2018-01865)

16 Ali SR, Lucas-Herald A, Bryce J \& Ahmed SF. The role of international databases in understanding the aetiology and consequences of differences/disorders of sex development. International Journal of Molecular Sciences 201920 9. (https://doi.org/10.3390/ ijms20184405)

17 Orimadegun A \& Omisanjo A. Evaluation of five formulae for estimating body surface area of Nigerian children. Annals of Medical and Health Sciences Research 20144 889-898. (https://doi. org/10.4103/2141-9248.144907)

18 Hindmarsh PC. Management of the child with congenital adrenal hyperplasia. Best Practice and Research: Clinical Endocrinology and Metabolism 200923 193-208. (https://doi.org/10.1016/j. beem.2008.10.010)

19 Rivkees SA \& Crawsford JD. Dexamethasone treatment of virilizing congenital adrenal hyperplasia: the ability to achieve normal growth. Pediatric Research 199741 71A. (https://doi.org/10.1542/ peds.106.4.767)

20 Whittle E \& Falhammar H. Glucocorticoid regimens in the treatment of congenital adrenal hyperplasia: a systematic review and metaanalysis. Journal of the Endocrine Society 20193 1227-1245. (https:// doi.org/10.1210/js.2019-00136)

21 Bonfig W, Bechtold S, Schmidt H, Knorr D \& Schwarz HP. Reduced final height outcome in congenital adrenal hyperplasia under prednisone treatment: deceleration of growth velocity during puberty. Journal of Clinical Endocrinology and Metabolism 200792 1635-1639. (https://doi.org/10.1210/jc.2006-2109)

22 Punthakee Z, Legault L \& Polychronakos C. Prednisolone in the treatment of adrenal insufficiency: a re-evaluation of relative potency. Journal of Pediatrics 2003143 402-405. (https://doi. org/10.1067/S0022-3476(03)00294-4)

23 Inada H, Imamura T, Nakajima R \& Yamano T. Poor response to substitution therapy with cortisone acetate in patients with congenital adrenal hyperplasia. Clinical Pediatric Endocrinology 2004 13 11-15. (https://doi.org/10.1297/cpe.13.11)

24 Whorwood CB \& Warne GL. A possible defect in the inter-conversion between cortisone and cortisol in prepubertal patients with congenital adrenal hyperplasia receiving cortisone acetate therapy. Journal of Steroid Biochemistry and Molecular Biology 199139 461-470. (https://doi.org/10.1016/0960-0760(91)90239-2)

25 Paizoni L, Auer MK, Schmidt H, Hübner A, Bidlingmaier M \& Reisch N. Effect of androgen excess and glucocorticoid exposure on metabolic risk profiles in patients with congenital adrenal hyperplasia due to 21-hydroxylase deficiency. Journal of Steroid
Biochemistry and Molecular Biology 2020197 105540. (https://doi. org/10.1016/j.jsbmb.2019.105540)

26 Auer MK, Paizoni L, Hofbauer LC, Rauner M, Chen Y, Schmidt H, Huebner A, Bidlingmaier M \& Reisch N. Effects of androgen excess and glucocorticoid exposure on bone health in adult patients with 21-hydroxylase deficiency. Journal of Steroid Biochemistry and Molecular Biology 2020204 105734. (https://doi.org/10.1016/j. jsbmb.2020.105734)

27 Charmandari E, Johnston A, Brook CG \& Hindmarsh PC. Bioavailability of oral hydrocortisone in patients with congenital adrenal hyperplasia due to 21-hydroxylase deficiency. Journal of Endocrinology 2001169 65-70. (https://doi.org/10.1677/ joe.0.1690065)

28 Groves RW, Toms GC, Houghton BJ \& Monson JP. Corticosteroid replacement therapy - twice or thrice daily? Journal of the Royal Society of Medicine 198881 514-516. (https://doi. org/10.1177/014107688808100906)

29 Mah PM, Jenkins RC, Rostami-Hodjegan A, Newell-Price J, Doane A, Ibbotson V, Tucker GT \& Ross RJ. Weight-related dosing, timing and monitoring hydrocortisone replacement therapy in patients with adrenal insufficiency. Clinical Endocrinology 200461 367-375. (https://doi.org/10.1111/j.1365-2265.2004.02106.x)

30 Howlett TA. An assessment of optimal hydrocortisone replacement therapy. Clinical Endocrinology 199746 263-268. (https://doi. org/10.1046/j.1365-2265.1997.1340955.x)

31 Minnetti M, Hasenmajer V, Pofi R, Venneri MA, Alexandraki KI \& Isidori AM. Fixing the broken clock in adrenal disorders: focus on glucocorticoids and chronotherapy. Journal of Endocrinology 2020246 R13-R31. (https://doi.org/10.1530/JOE-20-0066)

32 Porter J, Blair J \& Ross RJ. Is physiological glucocorticoid replacement important in children? Archives of Disease in Childhood 2017102 199-205. (https://doi.org/10.1136/archdischild-2015-309538)

33 Plat L, Leproult R, L'Hermite-Baleriaux M, Fery F, Mockel J, Polonsky KS \& Van Cauter E. Metabolic effects of short-term elevations of plasma cortisol are more pronounced in the evening than in the morning. Journal of Clinical Endocrinology and Metabolism 199984 3082-3092. (https://doi.org/10.1210/jcem.84.9.5978)

34 Osterberg L \& Blaschke T. Adherence to medication. New England Journal of Medicine 2005353 487-497. (https://doi.org/10.1056/ NEJMra050100)

35 Charmandari E, Hindmarsh PC, Johnston A \& Brook CGD. Congenital adrenal hyperplasia due to 21-hydroxylase deficiency: alterations in cortisol pharmacokinetics at puberty. Journal of Clinical Endocrinology and Metabolism 200186 2701-2708. (https://doi. org/10.1210/jcem.86.6.7522)

36 Moore JS, Monson JP, Kaltsas G, Putignano P, Wood PJ, Sheppard MC, Besser GM, Taylor NF \& Stewart PM. Modulation of $11 \beta$-hydroxysteroid dehydrogenase isozymes by growth hormone and insulin-like growth factor: in vivo and in vitro studies. Journal of Clinical Endocrinology and Metabolism 199984 4172-4177. (https:// doi.org/10.1210/jcem.84.11.6108)

37 Niranjan U \& Natarajan A. Congenital adrenal hyperplasia in children - a survey on the current practice in the UK. Journal of Pediatric Endocrinology and Metabolism 201528 847-851. (https://doi. org/10.1515/jpem-2014-0362)

38 Claahsen-van der Grinten HL, Noordam K, Borm GF \& Otten BJ. Absence of increased height velocity in the first year of life in untreated children with simple virilizing congenital adrenal hyperplasia. Journal of Clinical Endocrinology and Metabolism 200691 1205-1209. (https://doi.org/10.1210/jc.2005-1701)

39 Thilén A, Woods KA, Perry LA, Savage MO, Wedell A \& Ritzén EM. Early growth is not increased in untreated moderately severe 21-hydroxylase deficiency. Acta Paediatrica 199584 894-898. (https://doi.org/10.1111/j.1651-2227.1995.tb13788.x)

40 Bonfig W \& Schwarz HP. Growth pattern of untreated boys with simple virilizing congenital adrenal hyperplasia indicates 
relative androgen insensitivity during the first six months of life. Hormone Research in Paediatrics 201175 264-268. (https://doi. org/10.1159/000322580)

41 Stikkelbroeck NMML, van't Hof-Grootenboer BAE, Hermus ARMM, Otten BJ \& van't Hof MA. Growth inhibition by glucocorticoid treatment in salt wasting 21-hydroxylase deficiency: in early infancy and (pre)puberty. Journal of Clinical Endocrinology and Metabolism 200388 3525-3530. (https://doi.org/10.1210/jc.2002-030011)

42 Sellick J, Aldridge S, Thomas M \& Cheetham T. Growth of patients with congenital adrenal hyperplasia due to 21-hydroxylase in infancy, glucocorticoid requirement and the role of mineralocorticoid therapy. Journal of Pediatric Endocrinology and Metabolism 201831 1019-1022. (https://doi.org/10.1515/jpem-20180260)

43 Mooij CF, Kroese JM, Claahsen-van der Grinten HL, Tack CJ $\&$ Hermus ARMM. Unfavourable trends in cardiovascular and metabolic risk in paediatric and adult patients with congenital adrenal hyperplasia? Clinical Endocrinology 201073 137-146. (https:// doi.org/10.1111/j.1365-2265.2009.03690.x)

44 Han TS, Walker BR, Arlt W \& Ross RJ. Treatment and health outcomes in adults with congenital adrenal hyperplasia. Nature Reviews: Endocrinology 201410 115-124. (https://doi.org/10.1038/ nrendo.2013.239)
45 Mooij CF, Webb EA, Claahsen van der Grinten HL \& Krone N. Cardiovascular health, growth and gonadal function in children and adolescents with congenital adrenal hyperplasia. Archives of Disease in Childhood 2017102 578-584. (https://doi.org/10.1136/ archdischild-2016-311910)

46 Martinerie L, Pussard E, Foix-L'Hélias L, Petit F, Cosson C, Boileau P \& Lombès M. Physiological partial aldosterone resistance in human newborns. Pediatric Research 200966 323-328. (https://doi. org/10.1203/PDR.0b013e3181b1bbec)

47 Gomes LG, Madureira G, Mendonca BB \& Bachega TA. Mineralocorticoid replacement during infancy for salt wasting congenital adrenal hyperplasia due to 21-hydroxylase deficiency. Clinics 201368 147-152. (https://doi.org/10.6061/clinics/2013(02) oa05)

48 Maccabee-Ryaboy N, Thomas W, Kyllo J, Lteif A, Petryk A, GonzalezBolanos MT, Hindmarsh PC \& Sarafoglou K. Hypertension in children with congenital adrenal hyperplasia. Clinical Endocrinology 201685 528-534. (https://doi.org/10.1111/cen.13086)

49 Bonfig W \& Schwarz HP. Blood pressure, fludrocortisone dose and plasma renin activity in children with classic congenital adrenal hyperplasia due to 21-hydroxylase deficiency followed from birth to 4 years of age. Clinical Endocrinology 201481 871-875. (https://doi. org/10.1111/cen.12498)

Received 29 October 2020

Revised version received 12 January 2021

Accepted 15 January 2021 